Trab. Ling. Aplic., Campinas, (43): 19-34, Jan./Jun. 2004

\title{
CRENÇAS E VALORES SOBRE A ESCRITA EM MANUAIS ESCOLARES DE LÍNGUA MATERNA PARA O ENSINO MÉDIO*
}

\author{
CLÉCIO BUNZEN \\ (Mestrando em Lingüística Aplicada - UNICAMP)
}

\begin{abstract}
Based on new studies of literacy (Barton, Hamilton, Kleiman, Rojo,Signorini, Sreet), this paper was designed to provide the discussion of the set of values and beliefs about writing identified in three secondary school textbooks for mother-tongue Portuguese. In the first part of the article, we comment briefly on the relations between school literacy, the culture of writing and textbooks. After that, we analyze six chapters of the textbooks which are concerned with writing, the history of writing, or the relation between writing and the spoken language. The analysis suggests the existence of a set of beliefs which may help understand writing practices within school literacy. On the one hand, we have observed that students in secondary schools are commonly treated as non-writers and/or non-readers. This attitude serves not only as a model of autonomous literacy (Street, 1984), but also as a model of society. On the other hand, the textbooks are themselves in conflict in relation to values and beliefs about writing, such as what good writing is and the kind of writing that should be taught in the secondary school. Considering these issues, our research suggests that understanding (des)established values and beliefs about writing has become a crucial aspect of the teaching and learning process, at least insofar as inculcating patterns of behavior and values actually reproduces and consolidates the social order.
\end{abstract}

Keywords: Values and beliefs, teaching writing, Portuguese as a mother tongue

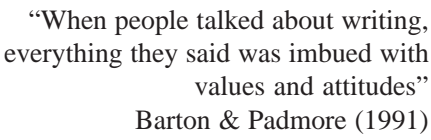

\section{INTRODUÇÃO}

Este trabalho tem como objetivo discutir crenças e valores sobre a escrita em recentes manuais escolares de língua portuguesa para o Ensino Médio. No entanto, para se entender, como defende Barton (1991), as maneiras de representação (crenças, valores, imagens, etc.) sobre a escrita, precisamos primeiramente assumir que estamos falando sobre crenças e valores construídos em esferas ou instituições diferentes: o trabalho, a família, a igreja ou

* Este trabalho está inserido no âmbito do Projeto Integrado "Práticas de escrita e de reflexão sobre a escrita em contextos de ensino" (CNPq- No 520427/2002-5). 
a escola. No século XVI, na Alemanha, por exemplo, Lutero preconizou a implantação da educação compulsória, argumentando que o descaso com a aprendizagem teria como resultado "a ira divina, a inflação, a praga e a sífilis, tiranos sanguinolentos, guerras e revoluções, a destruição de todo o país pelos turcos e tártaros, e até mesmo a restauração do poder papal". (Olson, 1997:22).

Como já assinalava Street (1984), os significados do letramento dependem sobremaneira das instituições sociais, uma vez que elas moldam os sentidos e as práticas de leitura e escritura. Por esse motivo, estudar o letramento significa não apenas compreender as práticas sociais, mas também "os vários conceitos, normas, valores e funções socioculturais subjacentes ao que é considerado um desempenho letrado numa dada situação" (Signorini, 2001:10).

Nesse "novo" olhar para as práticas de letramento, a escola deixa de ser vista como o único local onde podemos aprender e refletir sobre a escrita, uma vez que as pessoas refletem sobre a escrita em outros domínios da vida cotidiana de maneiras bem diversas e culturalmente relacionadas. Em outras palavras, as práticas de letramento são situadas e não podem ser tratadas de uma maneira universal (Barton \& Hamilton, 2000). Como assinalou Signorini (2001:125), "a filiação do estudo da escrita ao letramento significa, pois, compreendê-la não como um objeto único, estático e autônomo, sempre o mesmo em diferentes suportes, momentos e situações".

Entretanto, não podemos negar que as crenças e os valores sobre a escrita veiculados e proclamados, na esfera escolar, influenciam o modo como os professores e alunos agem dentro dessa instituição e fora dela, como já mostraram alguns trabalhos de base etnográfica (Heath, 1983; Street, 1984, Street \& Street, 1991). Ou seja, não se pode, então, esquecer que a escola forma um ponto de referência importante para os valores e atitudes dos alunos, tornando a escrita escolar um bem cultural desejável. Com bem disse Barton (1994:179): as atitudes e os valores escolares influenciam a sociedade em geral e é provavelmente verdade que a visão do público geral sobre leitura e escrita é influenciada pelas definições e imagens que circulam nas escolas.

Desta forma, resolvemos desenvolver uma pesquisa de cunho descritivo e interpretativo sobre crenças e valores sobre a escrita em manuais escolares de língua materna para o Ensino Médio, pois tal discussão nos ajudará a entender melhor que concepções estão sendo reforçadas ou desvalorizadas em relação à ação de escrever. Neste posicionamento, não podemos deixar de perceber como tais manuais interpretam o que seja língua(gem), uma vez que os modos de conceber esta organizam as formas como se define e mesmo como se trabalha com aquela.

O presente trabalho encontra-se, assim, dividido em duas seções. Em um primeiro momento, discutiremos brevemente o letramento escolar e sua relação com o livro didático. Em seguida, apresentaremos uma discussão sobre algumas crenças e valores sobre a escrita, encontradas em três manuais escolares de Ensino Médio, a saber: Ernani e Nicola (2000); Abaurre, Fadel e Pontara (2001) e Infante (2000). 


\section{MANUAIS ESCOLARES DE LÍNGUA MATERNA: LETRAMENTO ${ }^{1}$ E SABERES ESCOLARES}

Em nossos últimos trabalhos (Bunzen, $2003 \mathrm{a} \mathrm{e} \mathrm{b),} \mathrm{temos} \mathrm{procurado} \mathrm{compreender} \mathrm{o}$ livro didático como uma fonte interessante (ainda que complexa) para o estudo do cotidiano e dos saberes escolares, mais do que propriamente um objeto de estudo utilizado apenas para apontar "defeitos" ou para ver se as teorias acadêmicas estão sendo "transpostas" de forma coerente para o manual escolar. Como defende Batista (1999:533): "ao contrário da idéia difundida de que os saberes escolares e, particularmente os livros didáticos, consistiriam apenas uma adaptação simplificada, para fins escolares, de conteúdos produzidos no campo da cultura e da ciência, [...] investigações vêm evidenciando que a origem desses saberes e objetos é bem mais complexa e que, muitas vezes, é à escola e a seus livros que se deve atribuir a origem de conhecimentos e saberes posteriormente apropriados pelas esferas do conhecimento erudito e científico".

Por esse motivo, frisamos que o conhecimento escolar que emerge desses livros faz parte da construção heterogênea do saber docente (cf. Tardif, 2001) e das práticas de letramento dos professores e dos alunos. Não podemos esquecer também que os livros didáticos são frutos das disciplinas escolares, criadas especificamente para fins de ensino. Desta forma, como sugere Gimeno Sacristán (apud Lopes, 2002), os conhecimentos acadêmicos ou científicos são transformados, na escola, por processos de pedagogização ou de mediação didática dos saberes.

Vicent et al. (apud Munakata 2001:90) afirmam que a forma escolar de relações sociais é a forma social constitutiva do que se pode denominar uma relação escrituralescolar com a língua e com o mundo. Em outras palavras, "o modo de socialização escolar é, pois, indissociável da natureza escritural dos saberes a transmitir”. São justamente para essa esfera escolar e para essa forte relação com o mundo da escrita que historicamente foram criados e adaptados diversos impressos (cf. Batista, 1999; Munakata, 2001; Bunzen, 2002). Além disso, os saberes escolares só podem se tornar acessíveis quando são "semiotizados e veiculados através de textos orais e escritos" (Rafael, 2003:107). Essa é mais uma razão para um olhar atento sobre os saberes a serem ensinados, veiculados nos livros didáticos, uma vez que eles “devem permanecer suficientemente próximos dos saberes científicos, a fim de que não se incorra na negação desses saberes, e devem também aparecer como suficientemente distintos dos saberes do senso comum e dos saberes dos pais, para que seja preservada a própria legitimidade do ensino escolar" (Chevallard, apud Rafael, 2003:92).

Nesse contexto, concordamos com Batista (1999) e Rojo (2003), ao descrever a relação cultura escrita, livro didático e letramento. Segundo os autores, os livros didáticos

\footnotetext{
${ }^{1}$ Estamos concebendo letramento, neste trabalho, como as inúmeras práticas sociais que integram direta ou indiretamente a produção e/ou leitura de materiais escritos e que integram a dinâmica da vida cotidiana de uma dada comunidade (cf. Barton e Hamilton, 1998). É nesta direção que podemos falar também de letramento escolar e não mais tratar essa relação como dois pólos opostos: letramento x escolarização. Para Rojo (2001:70), "escola é letramento e dele decorre, quer suas práticas sejam orais ou escritas; quer haja ou não texto escrito sendo utilizado na sala de aula. Logo, só é admitida a forma composicional adjetiva: 'letramento escolar' ". Para um aprofundamento da questão ver Kleiman (1995).
} 
são, para parte significativa da população brasileira, o principal impresso em torno do qual o letramento escolar é organizado e construído. É neste sentido que a escola é uma instituição de ensino do "ler" e do "escrever", ou seja, uma instituição a quem é delegada a incumbência de pensar e de colocar intencionalmente em ação ferramentas que permitam o domínio de alguns saberes específicos, socialmente legitimados, como a escrita. Por este motivo, os livros didáticos, especialmente os de ensino de língua materna, constituem em uma fonte valiosa de dados para entendermos crenças, valores e concepções presentes na cultura escolar sobre a escrita. Os saberes provenientes dos livros didáticos de língua materna, de uma forma ou de outra, interferem na construção do que seja a escrita ou o ato de escrever desses alunos e professores em contextos escolares ou não-escolares. Assim, duas questões de pesquisa inter-relacionadas direcionaram nosso olhar:

a) Quais conceitos, crenças e valores sobre a escrita estão presentes nesses manuais?

b) Que conceitos estão sendo reforçados/desvalorizados em relação à ação de escrever?

\subsection{0 corpus da pesquisa}

Para responder as questões de pesquisa mencionadas acima, selecionamos, em um primeiro momento, um total de 5 coleções de Ensino Médio, publicadas nos últimos três anos (2000-2003). Assim, foi possível fazer uma análise geral para saber onde poderíamos encontrar tais concepções sobre a escrita nesses manuais. Verificamos, então, que a(s) concepções(s) sobre escrita estavam subjacentes em todas as unidades se olharmos detalhadamente para os textos selecionados ou para os tipos de atividades de leitura e/ou de produção de texto solicitadas ${ }^{2}$. Resolvemos, dessa maneira, fazer um recorte metodológico e concentrar nosso olhar nos livros didáticos que traziam unidades didáticas especificamente sobre a escrita, sua origem ou sobre sua relação com a oralidade. Assim, nos dedicamos aos conceitos explícitos sobre a escrita ou sobre a ação de escrever presentes em três coleções: Infante (2000), Ernani \& Nicola (2001), Abaurre et all. (2001). Selecionamos, então, seis unidades, duas de cada manual, para compor nosso corpus:

\begin{tabular}{|l|l|}
\hline Manuais & Títulos das unidades didáticas analisadas \\
\hline \multirow{3}{*}{ Manual 1 } & Unidade 2: Língua Falada e Língua escrita \\
\cline { 2 - 2 } & Unidade 10: O texto escrito (1) \\
\hline \multirow{3}{*}{ Manual 2 } & Unidade 1: Pensar, ler e escrever \\
\cline { 2 - 2 } & Unidade 12: A força da palavra escrita \\
\hline \multirow{3}{*}{ Manual 3 } & Unidade 1: A linguagem \\
\cline { 2 - 2 } & Unidade 2: A escrita \\
\hline
\end{tabular}

${ }^{2}$ Um outro aspecto que está sendo analisado, ainda no âmbito desse projeto integrado, é como os manuais mobilizam saberes específicos sobre o ensino de língua escrita (cf. Bunzen e Torres, 2003). 
Além das seis unidades didáticas, achamos pertinente levar em consideração algumas informações sobre a escrita presentes nas cartas de apresentação (doravante CA) dos livros didáticos, assim como nos manuais do professor (doravante MP). Essa escolha deve-se principalmente à noção de que o livro didático é destinado tanto ao aluno como ao professor. Em outras palavras, os autores deverão explicitar o que é a escrita tanto para quem está na escola com o papel de aprendiz, quanto para quem vai ensinar a escrita - o professor de língua portuguesa. O livro tem, então, o papel de fazer pelo menos duas mediações, como sugere Plane (apud Batista, 1999): uma mediação entre "o aluno e os saberes e práticas" e uma mediação entre "aluno e professor". É importante frisar que não estamos analisando os materiais didáticos com o objetivo de perceber o que acontece em locus, ou seja, a "verdadeira realidade" de sala de aula. Sabemos, por diversas razões, que o nosso objeto de pesquisa apresenta limitações. Não podemos, por exemplo, via livro didático estudar que conteúdos foram realmente ensinados ou que conteúdos foram realmente aprendidos pelo aluno. Segundo Bordet (1998:44), um mesmo livro didático pode ser objeto de utilizações muito diferentes.

\section{CONSTRUINDO A VISÃO DE PRODUTOR DE TEXTOS}

Antes de falar sobre a escrita e refletir sobre sua função no espaço escolar, os manuais escolares de língua materna constróem um papel ou uma representação social para esse aluno de Ensino Médio, usuário direto do manual. Por esta razão, achamos importante tecer alguns comentários sobre como o aluno de Ensino Médio é visto em sua relação com a ação de escrever.

Desde a carta de apresentação do livro didático - local geralmente destinado para explicação dos objetivos do livro -, encontramos a construção de uma imagem de aluno de Ensino Médio que ora não domina "naturalmente a escrita", ora não tem consciência da função social do ato de escrever, como podemos inferir dos fragmentos:

[1] "Nosso objetivo será alcançado quando a escrita e a leitura nos parecerem atos tão naturais quanto a fala" (CA do Manual 3);

[2] "Aptos para usá-la [linguagem] de forma consciente, teremos nos tornado cidadãos mais bem preparados para a vida na sociedade do novo milênio" (CA do Manual 2); [3] "Escrever é a forma de garantir nossa inserção na vida social, de nos tornarmos cidadãos de fato e de direito" (CA do Manual 2).

O aluno de Ensino Médio, de forma geral, é visto como um "ansioso produtor de texto" (CA do Manual 2) ou como um não produtor consciente de textos escritos. Ao lermos os fragmentos acima, percebemos claramente que há um papel que deverá ser desempenhado pelo aluno para poder se "tornar um cidadão mais preparado": aprender realmente a escrever "bem". É importante ressaltar a importância de perceber essa representação, pois o modo como as pessoas agem não está apenas relacionado com as suas habilidades, mas é influenciado em grande parte pelos papéis construídos socialmente (Barton, 1991). Segundo o autor, as pessoas aprendem que socialmente há papéis que são 
mais apropriados e outros não. Dessa maneira, os livros de didáticos, para ensinarem os alunos a "escrever melhor", reproduzem a imagem de um "aluno não produtor de textos" ou que não escreve de forma tão natural quanto fala ${ }^{3}$, etc. O saber a ser ensinado, aqui, procura se distanciar do saber do senso comum - as práticas de escrita do aluno em ambiente não escolar - e aponta para uma função social que caberá à instituição escola resolver: formação de um cidadão preparado para interagir através da escrita na sociedade do novo milênio ${ }^{4}$. É por meio também dessa construção que podemos entender alguns valores morais e sociais impregnados na noção de escrita escolar. Passaremos agora, então, a tecer comentários sobre algumas crenças e valores sobre a escrita que encontramos nas seis unidades didáticas dos livros analisados. Nossa análise terá como objetivo principal mostrar que tanto nas seleções nos textos, nas atividades propostas ou no próprio texto didático encontraremos tais concepções sobre a escrita, muitas vezes, em conflito dentro do próprio manual.

\section{CRENÇAS E VALORES SOBRE A ESCRITA NOS MANUAIS DE ENSINO MÉDIO}

Nas seis unidades didáticas analisadas, de forma geral, os manuais têm como objetivo fazer com que os alunos adquiram consciência da importância da escrita para nossa sociedade. Para realizar tal objetivo, os manuais abordam temas como: a origem da escrita, a relação oral x escrito e/ou sobre o processo de escrever.

Os conteúdos a serem ensinados - a própria ação de escrever ou o que é a escrita são normalmente explorados através de informações dadas pelos autores sobre a escrita ou através de retextualização ${ }^{5}$ de textos acadêmicos ou de divulgação científica que tratem do tema. O Manual 2, por exemplo, no capítulo "Pensar, ler e escrever", traz um fragmento do livro "Manual de Expressão Oral e Escrita” de Joaquim Mattoso Câmara Jr. (1983 p.58-9). O fragmento deste livro é utilizado, segundo os autores, para destacar que "os alunos já produzem textos o tempo todo nas mais variadas situações e para variados interlocutores em sua vida cotidiana. O trabalho com textos no ambiente escolar tem um caráter de

${ }^{3}$ Rojo (1995:66) demostra que uma das crenças em relação à escrita é justamente considerá-la como “um artefato contraposto à naturalidade da fala”. Ver a escrita com algo não natural implica necessariamente aprendêla em contextos especializados, no caso a escola, através de técnicas específicas planejadas artificialmente, como sugere a autora.

${ }^{4}$ Essa visão talvez seja fruto da visão de que a escrita é o órgão do progresso social. Segundo Olson (1997:21), "admite-se de modo geral que foi a difusão da leitura e da escrita que criou as instituições racionais e democráticas da sociedade, assim como o desenvolvimento industrial e o crescimento econômico; e que um declínio nos graus de alfabetização representa uma ameaça para qualquer sociedade progressista e democrática".

${ }^{5}$ Estamos utilizando o termo retextualização, neste artigo, para o processo de alteração e edição por que passam os textos publicados em outros veículos (jornais, livros, revistas) e que passam a compor o livro didático. Uma entrevista impressa, por exemplo, ao ser retextualizada para fins didáticos pode sofrer diversas alterações: mudança de título, de diagramação; cortes de fragmentos, de imagens, etc. É justamente esse processo de retextualização que ocasiona a mudança do gênero: a entrevista com as diversas alterações passa agora a fazer parte do gênero livro didático. 
treinamento, de reflexão (insistimos na tríade uso-reflexão-uso), para se atingir uma expressão proficiente” (MP do Manual 2).

No entanto, muito mais do que reforçar a idéia de que o aluno já é um produtor de textos, o fragmento explicita o que é necessário para escrever "bem": "a arte de escrever precisa assentar numa atividade preliminar já radicada que parte do ensino escolar e de um hábito de leitura inteligentemente conduzido; depende muito, portanto, de nós mesmos, de uma disciplina mental adquirida pela autocrítica e pela observação cuidadosa do que outros com bom resultado escreveram" (Mattoso Câmara Jr.). Ao trazer esse fragmento, o manual contribui para a visão da necessidade de produzir redações no espaço escolar e aponta também, conscientemente ou não, para um visão de escrita "artística", relacionada "ao hábito de leitura inteligentemente conduzido". Desta forma, não é qualquer leitura que será válida ${ }^{6}$. O fragmento retirado do livro de Mattoso Câmara serve muito mais como um "manual de instrução" que aconselha o aluno para o que deve ser feito para poder escrever melhor: ler textos clássicos e observar cuidadosamente o que "outros com bons resultados escreveram". Um dos exercícios de compreensão de texto realizado com o fragmento é esclarecedor nesse aspecto, uma vez que assume explicitamente que as atividades de produção de texto são "um mero exercício formal", mas são "úteis". Vejamos a atividade:

[4] "Embora seja um mero exercício formal, a prática de produção de textos na escola é útil e aparece justificada em algumas passagens do texto de Mattoso Câmara. Aponte uma dessas passagens". (Manual 2:16).

No geral, percebemos que o objetivo principal dessas unidades didáticas sobre a escrita é conscientizar os alunos da importância de escrever o gênero "redação escolar" prática escrita principal do letramento escolar, como podemos perceber no excerto abaixo retirado do capítulo "A linguagem” do Manual 3:

[5] "Essas considerações [relação entre a oralidade e a escrita] permitem entender por que a modalidade oral é aprendida espontaneamente pelas crianças, enquanto a modalidade escrita exige um longo processo de instrução formal. O ensino institucional da escrita pressupõe a exposição a diferentes tipos de texto escrito, assim como a apresentação organizada dos recursos formais e de conteúdo que permitem não só a produção de textos coesos e coerentes nessa modalidade, mas também a boa compreensão da leitura de textos mais elaborados em termos de léxico e de sintaxe. Em outras palavras (e colocando essa discussão em termos com os quais você está muito familiarizado...): é por esse motivo que todos precisamos aprender redação na escola!"' (itálico nosso).

\footnotetext{
${ }^{6}$ Assim como as práticas de letramento se constituem historicamente, as concepções de leitura e de escrita acompanham as mudanças que ocorrem nas sociedades de forma geral. Neste sentido, algumas instituições tem (ou tiveram) o "poder" de ser a controladora dos tipos de leitura: a escola ou a igreja, por exemplo. E desta perspectiva que podemos dizer com Guedes-Pinto (2002:199) que existem "leituras não autorizadas", ou seja, leituras consideradas "ruins ou de baixa qualidade em relação a uma suposta leitura erudita ou de melhor qualidade, segundo a classificação da escola, alicerçada pela teoria literária”. Ver também Kleiman (2001).
} 
As práticas de escrita escolares são vistas aqui como o objeto cultural desejável, como comentamos no início deste trabalho. Assim, os manuais defendem claramente que os alunos "precisam aprender redação na escola" para poderem se engajar de forma plena em eventos de letramento não-escolares. A questão se torna mais complexa, ao se instaurar uma perspectiva de escrita na escola e fora dela. Os manuais, de forma geral, admitem que os alunos escrevem fora do ambiente escolar, mas que tais práticas precisam ser "revistas" ou realizadas mais conscientemente. Na tentativa de conscientizar os alunos de que eles usam a escrita em diversos contextos, encontramos comentários como:

[6] "você produz textos nas mais diversas situações. Se pensarmos, mais especificamente, nos textos escritos, no dia-a-dia, você é 'convocado' a escrever bilhetes, cartas, requerimentos, relatórios, etc. Se fecharmos mais ainda o círculo, na escola você também produz variados tipos de texto: o plano de um seminário e a teoria a ser apresentada nele..." ("Pensar, ler e escrever" no Manual 2).

No trecho acima, o aluno é visto como alguém que utiliza a escrita em várias situações: não escolares - "no dia-a-dia você é convocado a escrever bilhetes..." e escolares - "na escola você também produz...". O ato de escrever aqui é visto quase como algo natural. No entanto, em outros momentos, o aluno é representado como um produtor de textos deficiente, cabendo à escola ser o local de referência legitimado para transformá-lo em "um competente produtor de vários textos":

[7] “... mas lembre-se: o trabalho de produção de textos realizado nas aulas de português não tem como objetivo a revelação de escritores. O objetivo maior é criar condições para que o estudante se transforme num competente produtor dos vários textos que a vida lhe pede: um bilhete, uma carta, um trabalho escolar, uma petição, um memorando, um relatório, etc" (Manual 2:172).

Esse conflito sobre o papel da escrita na escola e na vida dos alunos é constante nos livros didáticos analisados. No MP desse mesmo manual, por exemplo, percebe-se isto muito claramente. Em alguns momentos, é função da escola conscientizar o aluno de que, no dia-a-dia, ele "produz textos das mais variadas modalidades, em diversos contextos para diversos interlocutores, sobre diversos assuntos". Desta forma, "o aluno perceberá que possui um saber e que, portanto, é capaz de exercitá-lo também no ambiente escolar". O exemplo [7], retirado do livro do aluno, já parece ir em outra direção: o aluno agora é visto como produtor deficiente de textos, até pragmáticos como a carta e o bilhete. Por essa razão, o objetivo da obra com relação ao processo de escrever não é fazer os alunos virarem "escritores", mas um competente produtor de textos. A questão que se coloca aqui é: os alunos já não seriam produtores de tais textos, como informava o MP? O que é ser, então, um produtor de textos competente? A noção de "competência" precisa estar bastante clara, pois é em função dela que todo o processo de produção de unidades didáticas e de atividades com produção de texto será (re)definido.

Não veríamos problemas em classificar grande parte do discurso desses manuais como pertencentes ao "modelo do discurso escrito utilitário" (Souza, 2001). Tal modelo 
proporciona a visão de uma hipótese deficitária ou de "afasia" em relação à escrita (Signorini, 2003). Os alunos de Ensino Médio são vistos pelos manuais como ainda não totalmente associados às práticas de escrita legitimadas socialmente. Desta forma, colabora-se para uma visão de escrita autônoma e "desvinculada de práticas discursivas, ideologias e estruturas de poder existentes numa determinada cultura" (Souza, 2001:173). Esse modelo utilitário, como sugere o autor com base no estudo de Scollon, uma vez naturalizado é aplicado indiscriminadamente para a produção de textos escolares. De outro lado, é interessante também perceber que de tais discursos sobre a escrita emergem concepções que promovem encontros e desencontros, aceitação e resistência, consenso e conflito. Selecionamos, então, algumas crenças que aparecem com bastante freqüência na obras analisadas e que nos ajudam a entender as visões que são lançadas sobre a escrita e sobre a ação de escrever.

\section{i) "A escrita como expressão do pensamento"}

Nos manuais 1 e 2 por exemplo, é comum a idéia de que para escrever bem o aluno deve possuir certas habilidades, tais como "saber pensar". É por esse viés que os livros afirmam que: "saber escrever pressupõe, antes de mais nada, saber ler e pensar" ou que “o pensamento é expresso por palavras, que são registradas na escrita, que por sua vezé interpretada pela leitura. Como essas atividades estão intimamente relacionadas, podemos concluir que quem não pensa (ou pensa mal) não escreve (ou escreve mal) e quem não lê (ou lê mal) não escreve (ou escreve mal)"(Manual 2).

Essa visão aristotélica da linguagem pode ser encontrada fortemente nos livros, ou seja, a linguagem é vista como manifestação do pensamento interior dos homens. Essa imagem nos convida a imaginar que a escola é um meio de desenvolvimento cognitivo, não apenas individual, mas filogenético. A questão é muito mais complexa, como assinala Marcuschi (1999), pois não podemos admitir a posição que toma a língua como um simples instrumento de representação. Para o autor, "as línguas não são formas de retratar o mundo, mas de tratar o mundo". Ainda segundo esta visão, podemos inferir que os alunos não sabem escrever, não sabem se expressar, por que não se preocupam em pensar. Então, primeiro o aluno teria de adquirir o hábito de pensar para depois ter condições de escrever. ${ }^{7}$

\section{ii) "Escreve bem, quem lê muito"}

Fortemente relacionada a essa última questão, percebemos a visão de que para escrever bem o aluno deve ler muito. Essa relação entre leitura e escrita, pelo menos em contexto escolar, ainda precisa ser repensada, pois podemos estar passando uma visão de escrita que não pode existir sem o hábito da leitura exaustiva. Dois fragmentos retirados dos manuais nos mostram como o letramento escolar visa relacionar fortemente leitura e escrita:

${ }^{7}$ Uma pesquisa, realizada por Lima (2003), com professores universitários de uma universidade particular do Curso de Letras mostra também enunciados semelhantes aos encontrados nos livros didáticos: i) "escrever é você colocar numa folha de papel suas idéias, os seus conceitos, o seu pensamento, enfim que tenha sentido" ou ii) "escrita é a materialização da linguagem. Quando eu quero colocar no papel meu pensamento. Manifestação concreta e visual do pensamento. 
[8] "Independente da quantidade e do tipo de escrita a ser produzido por qualquer um de nós, portanto, todos devemos ler muito e sempre. Devemos ler revistas e jornais (e, aí, não só as notícias e as seções de esporte e lazer, mas também as crônicas, os editoriais e os artigos e ensaios assinados por autores...) E devemos ler... LIVROS, muitos livros! Devemos ler livros sobre os assuntos que mais nos interessam e também bons livros de ficção (Manual 3)"

[9] "Ora, as idéias não surgem do nada; elas são fruto dos processos de comunicação dos quais participamos e das informações a que temos acesso vivenciando experiências, conversando e lendo, lendo, lendo (Manual 2)".

Os manuais afirmam categoricamente que escrita e leitura são duas faces de uma mesma atividade e que há uma forte relação entre a quantidade de leitura ("lendo, lendo, lendo") e a qualidade da produção textual. Apesar de acreditarmos que elas mantêm uma forte relação, não podemos afirmar categoricamente para os alunos que, ao se tornarem leitores de jornais e revistas e de gêneros de prestígio (crônica, artigo de opinião), se transformarão em bons produtores de texto. Afinal de contas, não se trata de uma questão de transferência de habilidades. Se assim o fizermos, estaremos construindo uma visão de escrita como um produto necessariamente associado as nossas práticas de "leitura de prestígio". Cria-se assim um "simulacro" do que é a escrita em ambientes escolares e nãoescolares. Em suma, trabalha-se com a noção de que a "a escrita é uma habilidade cujo domínio envolve a aquisição de uma técnica específica".

Podemos perceber também que uma das teses centrais defendidas em tal posicionamento é que a leitura (principalmente a literária) conduziria, como comenta Britto (2003b:48), à liberdade do espírito, à atividade intelectual crítica e autônoma. Em outras palavras, "conduziria a uma consciência cartesiana, em que se manifesta a razão equilibrada do sujeito universal". Assim, é necessário ler muito para escrever bem e se tornar de fato cidadão. Resta-nos saber, como também sugere o autor, se existirá efetivamente uma relação bem estabelecida entre ler e ser cidadão.

\section{iii) "O poder da escrita"}

O "mito do letramento", denominado por Graff (1979, apud Kleiman, 1995) para caracterizar a ideologia que reproduz os efeitos positivos tantos cognitivos quanto sociais advindos da escrita, (re)surge nos livros didáticos, por exemplo, ao darem à escrita um poder extraordinário, como percebemos desde os títulos das unidades "A força da palavra escrita". Encontramos, de forma geral, uma supervalorização da língua escrita, como podemos ver nos exemplos seguintes:

[10] "A escrita é, com certeza, uma das maiores criações do homem. Através dela podemos voltar ao passado, projetar-nos para o futuro e compreender o presente. A palavra escrita não só nos revela o mundo - ela é capaz de transformá-lo" (Manual 2). 
[11] "O homem sempre teve necessidade de registrar seus atos, seus pensamentos. Para isso, usa a linguagem, com destaque para a escrita. A escrita é tão importante que sua invenção marca a linha divisória entre a Pré-História e a História” (Manual 2).

A visão de que a escrita é uma grande invenção da humanidade está presente em todos os três manuais. Esse mito, como sugerem Gnerre (1985) e Marcuschi (2001), leva a uma posição de supremacia das culturas com escrita ou até mesmo dos grupos que dominam a escrita dentro de uma sociedade desigualmente desenvolvida, como a nossa. Essa idéia está diretamente relacionada à primeira- a escrita como expressão do pensamento, visto que a "escrita seria a responsável pelo pensamento silogístico, tendo em vista o fato de ela contribuir essencialmente para a descontextualização dos significados que criariam autonomia ao passarem da 'cabeça' para o 'texto no papel', fazendo assim surgir a descentralização do pensamento que passaria do concreto para o abstrato" (Marscuschi, 2001:30).

\section{iv) "A dicotomização entre oral e escrito"}

Aliada a essa visão de escrita autônoma, encontramos em dois manuais [Manual 1 e Manual 2] um tratamento dicotômico ao tratar as relações entre o oral e o escrito. Essa visão de língua reforça o modelo de letramento autônomo, criticado por Street (1984). Nesses manuais, a ênfase dada é na análise de diferenças entre as duas modalidades. Normalmente, trata-se, de uma análise que se volta apenas para o código, sem perceber a heterogeneidade dos usos da língua. Segundo Marcuschi (2001), esse tipo de visão deu origem ao prescritivismo de uma única norma lingüística tida como padrão e que está representada na denominada norma culta. Vejamos dois fragmentos dos livros que tentam explicitar essas diferenças para os alunos:

[12] "Na língua escrita, a elaboração da mensagem requer uma linguagem menos alusiva. $\mathrm{O}$ emprego de pronomes e de certos advérbios, eficientes e suficientes na língua falada, obedece a critérios diferentes, pois essas palavras passam a relacionar principalmente partes do texto, não mais designando dados da realidade exterior. Em seu lugar, vemo-nos obrigado a utilizar formas de referência mais precisas, como substantivos e adjetivos, capazes de nomear e caracterizar os seres. A língua escrita, assim, demanda um esforço maior de precisão..." (Manual 1: 37).

[13] "O código oral conta com elementos de expressividade que o código escrito não consegue reproduzir com muita eficiência” (Manual 1: 37).

Como podemos perceber, os fragmentos acima alimentam uma noção de língua escrita homogênea, sem maiores preocupações com as práticas sociais. O próprio sub-título da seção, em que se encontram os exemplos 12 e 13, já demonstra tal visão: "Língua escrita: mas de referência mais precisas". O texto retextualizado pelo Manual 1, intitulado de "O 
texto escrito", , por exemplo, também colabora com essa concepção homogênea de língua, uma vez que reforça a visão dicotômica entre oralidade e escrita:

[14] “A luta que os alunos enfrentam com relação à produção de textos escritos é muito especial. Em geral, eles não apresentam dificuldades em se expressar através da fala coloquial. Os problemas começam a surgir quando este aluno tem necessidade de se expressar formalmente e se agravam no momento de produzir um texto escrito. Nesta última situação ele deve ter claro que há diferenças marcantes entre falar e escrever" (Manual 1:340)

Acreditamos que desta forma os livros didáticos estão contribuindo para uma visão de língua estereotipada, principalmente, em relação aos usos sociais da escrita. De que escrita e de que fala estamos realmente falando? No entanto, seria redutor afirmar que todos os livros didáticos analisados têm essa visão extremamente dicotômica. O Manual 3, por exemplo, tem uma relação menos dicotômica em relação a tal aspecto, mas apresenta outras crenças ao tratar da relação oral x escrito:

[15] "A escrita não é um mero registro da fala, até porque surgiu para expressar diferentes necessidades comunicativas e intelectuais do ser humano. O nível de elaboração intelectual a que se pode chegar através do exercício da escrita é imenso, bastanto lembrar que, sem o suporte da escrita, determinados tipos de raciocínio lógico e filosófico talvez nem tivessem desenvolvido. Nesse sentido, pode-se dizer que o exercício da atividade de escrever levou a humanidade, através dos tempos, a definir novos rumos para a evolução cognitiva” (Manual 3: 9)

O exemplo [15] aponta para o fato de "o nível de elaboração intelectual a que se pode chegar através da escrita é imenso". Essa afirmação está baseada no fato de que cabe à escrita proporcionar o desenvolvimento cultural e cognitivo. Por causa da escrita, 'determinados tipos de raciocínio lógico e filosófico talvez nem tivessem desenvolvido'. Segundo Olson (1997:29), isso seria um equívoco, pois o conhecimento pode ser transmitido de várias maneiras: "pela fala, escrita, gráficos, diagramas, gravações de som e de vídeo". Ao estabelecer um vínculo direto entre o desenvolvimento cultural dos povos a escrita, reforçamos a crença da superioridade intrínseca da escrita, conforme comentamos no item anterior. Entretanto, o Manual 3, logo após fazer o comentário acima, procura "amenizar" a questão, como podemos ver no exemplo a seguir:

[16] “ Mas atenção! Que não se conclua, a partir dessas considerações, que a escrita é "melhor" do que a oralidade, ou pior ainda, que os indivíduos que escrevem são mais inteligentes ou 'pensam melhor' do que os que não escrevem. Trata-se, na verdade, de diferentes modos de cognição e de expressão da realidade.” (Manual 3:9).

${ }^{8} \mathrm{O}$ fragmento foi retirado do livro "A magia da mudança: vestibular Unicamp - língua e literatura" de Regina H. de Almeida Durigan et al, publicado em 1987, pela Editora da Unicamp. 
O exemplo 16 nos mostra claramente como as concepções sobre escrita nos livros didáticos, assim como outros conceitos, não estão articulados de forma homogênea. Esses primeiros resultados apontam para percebermos o processo de concepção de livro didático e de produção de conhecimento escolar como algo que se caracteriza muito mais por uma incompletude e por uma heterogeneidade, do que num saber-fazer homogêneo e sem conflito. Por essa razão, a mobilização de tais conceitos está dentro de um processo de encontros e desencontros, de estabilização e desestabilização. Isso faz com que o olhar para o livro didático procure perceber o modo heterogêneo de aceitação e resistência dessas crenças e valores.

\section{ALGUMAS CONCLUSÕES}

O nosso olhar de analista, também impregnado de crenças e valores, procurou discutir um aspecto importante, mas muitas vezes deixado em segundo plano, para tratar a questão do ensino da escrita em sala de aula: que crenças e valores estamos atribuindo às práticas de escrita ou à ação de escrever? O resultado dessa pesquisa nos sugere uma outra pergunta: será que é exagerado o valor que damos à escrita? Longe de tentar responder, neste espaço, acreditamos que tais crenças e valores são produtos também de uma concepção do que seja ensinar língua escrita na escola. Não podemos esquecer que muitos trabalhos levantaram a questão de que uma educação formal levaria a distinguir entre o mundo e nossas idéias sobre o mundo (cf. Scribner, 1968), sem perceberem os aspectos políticos e ideológicos que integram tal posicionamento.

Como sugerimos neste trabalho, as crenças e valores sobre a escrita presentes no ambiente escolar e cristalizadas em muitos livros didáticos favorecem, na maioria das vezes, uma visão de escrita mecânica e autonôma (cf. Street, 1984). Ou seja, não podemos negar que ao desenvolver uma imagem da escrita da escola, criamos uma representação social para aquele aluno que é visto como um "sujeito incapaz de escrever" e para o professor de língua materna, que deve dar subsídios para que aquele aluno consiga se tornar um cidadão mais preparado através das práticas de redação escolar. Mais uma vez percebemos a complexidade de trabalhar com a escrita em ambientes escolares, principalmente com a tendência atual de trazer as práticas não-escolares (produção de gêneros diversos) para o ambiente escolar, proporcionando de alguma forma uma mudança de crenças e valores sobre a escrita. Além disso, não podemos perder de vista que a escolarização tem também uma função valorativa, "através da qual reafirma o conjunto de valores que informam o conceito hegemônico de sociedade, tais como o sentido de liberdade, de respeito, de autoridade, de superioridade, de propriedade, entre outros. Essa função, apesar de menos evidente, está imbricada na organização escolar e na função de ser da escola" (Britto, 2003a:44).

É nessa direção que entender as crenças e os valores sobre a escrita torna-se um aspecto essencial para o ensino e aprendizagem de língua materna, pois a inculcação de modelos de comportamento e de valores não deixam de reproduzir e reforçar um modelo de sociedade. Como percebemos, em nossa breve análise, os livros didáticos de língua materna para o Ensino Médio estão em conflito com eles mesmos em relação a que "modelo" 
BUNZEN - Crenças e valores sobre a escrita...

de escrita privilegiar, como tratar as práticas de letramento não-escolares dos alunos e como conscientizar os alunos da "importância" do ensino da produção de texto. E tal conflito, longe de ser visto como algo puramente negativo, reforça a idéia de que ensinar língua materna é também (des)construir representações, crenças, valores e atitudes sobre os usos da língua.

\section{REFERÊNCIAS BIBLIOGRÁFICAS}

BARTON, D. (1991). "The Social Nature of Writing". In: Barton, D. \& Ivanic, R. (orgs.) Writing in the Community. Newbury Park, London and New Delhi: Sage Publications, Inc.

(1994). Literacy: an introduction to the ecology of written language. Oxford and Cambridge: Blackwell.

BARTON, D. \& HAMILTON, M. (1998). Local Literacies. Reading and Writing in one community. London: Routledge.

. (2000). "Literacy Practices". In: Barton, D., Hamilton, M. e Ivanic, Roz. Situated literacies. London: Routledge.

BARTON, D. \& PADMORE, S. (1991) "Roles, networks, and values in everyday writing". In: Barton, D. \& Ivanic, R. (orgs.) Writing in the Community. Newbury Park, London and New Delhi: Sage Publications, Inc.

BATISTA, A. (1999). "Um objeto variável e instável: textos, impressos e livros didáticos". In: Márcia Abreu (org.) Leitura, história e história da leitura. Campinas, SP: Mercado de Letras.

BORDET, D. (1998) “La 'transformation des savoirs' dans l'enceint de la classe”. In: DEES 112.

BRITTO, L. P. (2003a) "Ensino da escrita x Ensino da norma". In: Britto, Luiz P. Contra o consenso: cultura escrita, educação e participação. Campinas: Mercado de Letras.

. (2003b) "Sociedade de cultura escrita, alfabetismo e participação". In: Ribeiro, Vera (org.). Letramento no Brasil: reflexões a partir do INAF 2001. São Paulo: Global.

BUNZEN, C. (2003 a). "Carta pessoal nos manuais escolares: letramento escolar?". Trabalho apresentado no $13^{\circ}$ INPLA, PUC-SP (no prelo).

(2003 b). "Gêneros interpessoais nos manuais escolares de Ensino Médio". Trabalho apresentado no $51^{\circ}$ Seminário do Gel, UNITAU-SP (no prelo).

. (2002). "Florilégio? Livro didático? Livro?" Trabalho apresentado no I Simpósio sobre Materiais Didáticos. UFPE. (mimeo).

BUNZEN, C. \& TORRES, T. (2003). "Mobilização de saberes específicos sobre o ensino de língua escrita em materiais didáticos" (em prep.).

GNERRE, M. (1985). Linguagem, escrita e poder. São Paulo: Martins Fontes.

GUEDES-PINTO, A. L. (2002). Rememorando trajetórias da professora-alfabetizadora: a leitura com prática constitutiva de sua identidade e formação de profissionais. Campinas: Mercado de Letras.

HEATH, S. (1983). Ways with words. Language. Life and Work in Communities and Classrooms. Cambridge, Cambridge University Press. 
KLEIMAN, A. (1995). "Modelos de letramento e as práticas de alfabetização na escola”. In: Kleiman, A. (org.). Os significados do letramento. Campinas: Mercado de Letras.

(2001). "Letramento e formação do professor: quais as práticas e exigências no local de trabalho?". In: Kleiman, A. (org.). A formação do professor: perspectiva da lingüística aplicada. Campinas: Mercado de Letras.

LIMA, R. C. (2003). "Concepções de escrita nos PCNs de Língua Portuguesa e em um curso de formação de professores”. In: Trabalhos em Lingüística Aplicada, № 41, Campinas.

LOPES, A. C. (2002). “Universidade e Escola: o diálogo entre saberes diversos”. (mimeo).

MARCUSCHI, L. A (2001). Da Fala para a Escrita: atividades de retextualização. $3^{\text {a }}$ Ed. São Paulo: Cortez. (1999). "Oralidade e escrita: uma ou duas leituras do mundo?" (mimeo).

MUNAKATA, K. (2001). “Livro didático e formação do professor são incompatíveis?”. Trabalho apresentado no Simpósio "O livro didático e a formação de professores". (mimeo).

OLSON, D. ([1994]1997). O mundo no papel: as implicações conceituais e cognitivas da leitura e da escrita. São Paulo: Ática.

RAFAEL, E. (2003). "Da lingüística à sala de aula: construção dos conceitos de texto e de coesão textual” (no prelo).

ROJO, R. (1995). “Concepções não-valorizadas de escrita: a escrita como 'um outro modo de falar"”. In: Kleiman, A. (org.). Os significados do letramento. Campinas: Mercado de Letras.

. (2001). "Letramento escolar, oralidade e escrita em sala de aula: diferentes modalidades ou gêneros do discurso?" In: Signorini, I. (org) Investigando a relação oral/escrito e as teorias do letramento. Campinas: Mercado de Letras.

(2003). "Cultura escrita e livro escolar: propostas para o letramento das camadas populares no Brasil" (no prelo).

SCRIBNER, S. (1997 [1968]). "The cognitive consequences of literacy”. In: Sylvia Scribner (org.) Mind and Social Practices. Ed. Pr E. Tobach, R. J Falmagne et al., Cambridge, University Press.

SIGNORINI, I. (2001). "Construindo com a escrita- 'outras cenas de fala"” In: Signorini, I. (org.) Investigando a relação oral/escrito e as teorias do letramento. Campinas: Mercado de Letras.

(2003). "Invertendo a lógica do projeto escolar de esclarecer o ignorante em matéria de língua". Trabalho apresentado no I Simpósio de Língua Portuguesa e Literatura: interseções PUC-Minas. (no prelo).

SOUZA, L. M. de. (2001). "Para uma ecologia da escrita indígena: a escrita multimodal Kaxinawá". In: Signorini, I. (org.) Investigando a relação oral/escrito e as teorias do letramento. Campinas: Mercado de Letras.

STREET, B. (1984). Literacy in Theory and Practice. Cambridge: Cambridge University Press.

STREET, J. \& STREET, B. (1991). “ The schooling of literacy”. In: Barton, D. e Ivanic R. (org.) Writing in the Community. Newbury Park, London and New Delhi: Sage Publications, Inc.

TARDIF, M. (2001). Saberes docentes e formação profissional. Editora Vozes, Petrópolis, RJ. 
BUNZEN - Crenças e valores sobre a escrita...

Obras didáticas utilizadas:

ABAURRE, Maria Luiza, Marcela, Pontara \& Fadel, Tatiana. (2000) Português: Língua e Literatura. São Paulo: Editora Moderna.

INFANTE, Ulisses. (2000). Textos: leituras e escritas: literatura, língua e redação. Volume 1. São Paulo: Scipione.

NICOLA, Ernani \& Nicola, José de (2001). Práticas de linguagem: leitura e produção textos. São Paulo: Scipione. 